\title{
Practitioners' Perception on the Critical Determinant of Uncertainty Factors that Influence Transaction Cost in Highway Construction Projects
}

\author{
* Zaigham Ali (Corresponding Author) \\ ** Dr. Ammar Hussain \\ *** Mehfooz Ullah
}

\begin{abstract}
The purpose of this paper is to ascertain practitioners' perception of the critical determinants of uncertainty factors on the transaction cost (TC) in highway construction projects. A survey questionnaire is used to collect data from the 230 practitioners of public-sector construction organizations in Pakistan to identify those factors. The partial least square structural equation modeling (PLS-SEM) is tested on the collected data. This research investigates that TC borne by the owner can be reduced when the owner minimizes inherent uncertainties. To reduce uncertainty, the owner needs to ensure a good relationship with the contracting parties, make a timely payment to the contractor, complete work scope to reduce change orders, enhancing the owner's experience in similar projects which increase the organizational efficiency hence reduce in TC. This empirical study was conducted from an organizational perspective which helps the project owners to overcome the issues under uncertainty that influence the Transaction cost (TC) in highway construction projects in developing countries. It demonstrates that the uncertainty that causes to enhance the TC is due to the uncertainty of the owner's behavior. This study provides a guideline for the practitioners of the public sector construction industry to bring cost efficiency under the uncertain circumstance.
\end{abstract}

Keywords: Construction Projects, Uncertainty, Transaction Cost, Contractor

Introduction

The construction projects are executed in the natural environment surrounded by uncertainties and risks (Shen, $\mathrm{Wu}, \& \mathrm{Ng}, 2001$ ). In design-bid-build (DBB) projects environment faces more challenges because various factors are involved in the process of project execution, which enhances uncertainty in projects. The uncertainty in simple English is the lack of certainty, while in the project its emphasis on variability from predefined time, cost, and objective. According to Williamson uncertainty in TCE, bring variation in the cost when it is operationalized with human as well as environmental factors (Williamson, 1975). The human factor involves roles and responsibilities, relationships, and expectations of contracting parties. While environmental factors carry unanticipated changes and circumstances to execute the contract (Li, Arditi, \& Zang, 2013), which cause to create an uncertain situation. In an economic organization, uncertainty is an important determinant that negatively influences the cost efficiency of projects (Greenwood \& Yates, 2006). In the contracting relationship, money is the medium of exchange between the trading partners, if it is a cost for an owner at the same time price to the contractor (Hillebrandt \& Hughes, 2000). Studies also confirm that highway construction projects, as compared to other infrastructure projects, are exposed to more uncertainties because highway projects are spread over a wider geographic area and expose to the risk of unexpected underground conditions (Sameh M. El-Sayegh \& Mansour, 2015). Moreover, the highway construction projects are inherently complex, costly with many variables ground condition such as spread over the more challenging terrain type, rocky and sandy areas. The presence of unidentified and unexpected underground utilities creates additional uncertainties in the process of construction (Reilly \& Brown, 2004), hence expose to TC escalation. However, TCE theory posits that uncertainty causes an unexpected increase in cost during trading relationships due to either or both parties'

* Department of Business Management, Karakoram International University, Gilgit-Baltistan, Pakistan Email: Zaigham.ali@kiu.edu.pk

** Department of Business Management, Karakoram International University, Gilgit-Baltistan, Pakistan Email: dr.ammar@ kiu.edu.pk

*** Department of Business Management, Karakoram International University, Gilgit-Baltistan, Pakistan Email: Mehfoozullah@kiu.edu.pk 
uncertain behavior (bounded rationality and opportunism) and uncertain project environment (unanticipated changes in the environment). The owner incurs two basic types of costs in any contracting business i.e., cost for contract preparation and cost for contract enforcement and monitoring which is known as Transaction cost (TC) (Williamson, 1985). Therefore, uncertainties enhance the probability to escalate the TC in all stages of the project life cycle (Atkinson, Crawford, $\&$ Ward, 2006). This study focuses on the uncertainty factors with the contention that it influences the TC over and above the production cost till project completion (Li et al., 2013).

The literature has discussed various sources and elements of uncertainty (Atkinson et al., 2006; Perminova, Gustafsson, \& Wikstrom, 2008; Turner \& Keegan, 2001; Winch, 1989). Some researchers used the TC framework to determine uncertainties for resource allocation (Reve \& Levitt, 1984). Most of the studies justified the form of governance based on uncertainty and TC (Milward, 1996; Miranda \& Lerner, 1995; Perry \& Babitsky, 1986; Wise, 1990). The uncertainty role in TCE theory is that it causes market failure because of unexpected increase increases in TC in any project (Shin, 2003). The influencing role of uncertainty to increase the TC is very critical which is understudied in the highway construction projects of Pakistan. Although, Guo et al. (2016) studied uncertainty factors and TC in general construction projects in the USA. Similarly, Ali, Zhu, \& Hussain, (2018) have discussed the uncertainty factors but limited responses were collected. However, the studies on the construction projects found that uncertainties are contextual due to which typical environmental scanning is required (Youker, 1992). Therefore, identification of those critical uncertainty factors in our context is expected to be different. Previous studies also confirmed that threats of uncertainties would be different in different cultural settings (Perminova et al., 2008). Moreover, organizational processes and mechanisms and employee behavior vary based on crosscultural differences (Hofstede, 2003). The cross-cultural variations acting under the prevailing norms may influence the TC differently. Thus, the application of research findings from developed countries in developing countries is questionable. Hence, significant research is still required to identify the determinants of TC in highway construction projects.

To help resolve this knowledge inadequacy, this study is conducted in Pakistan. The main question in this research is to ascertain determinants of uncertainty factors that influence TC in highway construction projects. This research, therefore, investigates this important line of empirical inquiry. There were three objectives formulated to conduct this study. Firstly, to find the critical determinants of uncertainty factors that influence TC performance. Secondly, to find the critical phases of a project that create uncertainty due to which TC increase. Finally, Implications for the policymakers to review the policies base on the identification of critical uncertain factors. The significance of this study is that it will contribute to the public sector construction industry to ascertain the influence of critical determinants of uncertainty on the TC borne by the owner. It also contributes to making proactive plans in the construction industry to reduce the cost escalation issues, especially in highway construction projects. In long run, the policymaker may consider reviewing the existing policies to overcome the post-contract cost escalation issues. In the following sub-section, we started with the comprehensive discussion on literature review followed by the hypothesis. The study then proceeds to discuss the methodology and data analysis. This paper concluded with a discussion, its practical implications, and limitations.

\section{Literature Review}

\section{Uncertainty and TCs in Construction Projects}

Uncertainty refers to a situation or an event that leads to alternate consequences which could be positive or negative. A risk is a quantitative approach of uncertainty in which the decision-maker gives probabilities to an outcome where every probability is greater than zero (Perminova et al. 2008). There are various uncertainties associated with the project life cycle, nature of the contract, and contracting parties due to which objectives of contracting parties do not align, work quality and reliability issues arise. The inability of each party to perform its responsibilities ultimately influences the project performance (Atkinson et al., 2006). Researchers argued that uncertainty could be the result of internal as well as external sources of a project which can influence the successful project performance (Coggan, Buitelaar, Whitten, \& Bennett, 2013; Jin \& Zhang, 2011; Li et al., 2013). The uncertainties in the external environment of an organization are legal, social, economic, and technological. While, uncertainties internal to the organizations are information systems, project location, corporate culture, and project finance (Grimm, Lee, \& Smith, 2006; Marcus \& Cohen, 2017; 
Perminova et al., 2008; Pride et al., 2006). These environments likely increase pre and post-contract TC (Rajeh, Tookey, \& Rotimi, 2015). The external and internal uncertainties in any project affect the contracting parties to incorporate comprehensive contingencies in the contract (Rajeh et al., 2015). Hence, TC can be the result of failure to manage uncertainties and inferior governance decisions, and other issues not under the direct control of the contracting parties. The cost for an uncertain external project environment causes unexpected delays on project sites because of strikes, law and order situations and extreme weather conditions may cause demands for rate revisions (Li et al., 2013). Similarly, political uncertainty in the country increases the cost of doing business because of work stoppage and delays which causes various expected work revisions (Collier \& Gunning, 1999). The owner responds to the changing external environment identifying potential threats and opportunities so that prompt decisions could be made (Perminova et al., 2008). Thus, uncertainties in the project environment lead to renegotiations (Mysen, Svensson, \& Payan, 2011), it provides opportunities for the contractor to get benefits in the form of numerous claims, unbalanced biding, additional work which could cause an antagonistic relationship of both parties which is ultimately ended up in dispute and claim (Rajeh et al., 2015).

\section{Explanation of the Construct and Hypothesis \\ Uncertainty of the construction project (UOCP)}

The UOCP is very critical because disputes and disagreements between the contracting parties are inevitable during project execution. The contract complexities can be avoided if the technical specifications are clear and completed with all respect (J. E. Diekmann \& Nelson, 1985). Otherwise, it increases the uncertainty in the transaction environment which has the TC (Farajian, 2010). The project uncertainty is the difference between the information required to do a task and the information which is already processed by contracting parties (Galbraith, 1973). In this situation both parties lacking information (Atkinson et al., 2006). When the uncertainty of the project is high it alters the initial drawings and design specifications during project executions which becomes problematic to settle for both contracting parties ( $\mathrm{Li}$, Arditi, \& Wang, 2015). To reduce uncertainty in a construction project, require a complete project design. The construction projects in the construction industry possess more risk than the other industry because of their complexities (Shen et al., 2001). Based on these findings, it is expected that uncertainty in construction projects could enhance the TC.

Hypothesis 1: TCs are higher if the construction project is uncertain.

\section{Uncertainty of Transaction Environment (UOTE)}

Weick (1977) argued that organizations should be proactive rather than reactive to control the project environment. To overcome UOTE, organizations need to specify the rights and responsibilities of both contracting parties in advance. The projects are complex endeavors (Perminova et al., 2008) and early identification of problems is difficult to make. For instance, risk prediction is difficult to make in advance and a clear disparity is found between the contracting parties' perception of risk allocation in contract clauses (Cheung \& Pang, 2013). If the whole risk is transferred to a contractor, it is responded to by increasing markups, which escalate the contract cost to the owner (Sameh Monir ElSayegh, 2008). The motivational incentive clauses are also commonly practiced in construction projects. For instance, the incentive and disincentive payments are based on the contractor's performance, in which the owner maintains the project duration to reduce the chance of abnormal cost escalation which can maximize contractors' profit (Broome \& Perry, 2002). TC escalation also depends upon the competitive procurement process, the higher the competitive procurement process, the higher will be the TC but in the case of weak competition total project cost can be escalated (Farajian, 2010).

Hence, the UOTE can be defined from the fair risk allocation, incentives or disincentives, integration between design and construction, competitive procurement process and early involvement of the contractor in design in construction projects reduces TC. It can be inferred that UOTE positively influences the TC. The transaction environment faces uncertainty while establishing project performance because various parties are involved other than the owner and agent (Atkinson et al., 2006). Our focus, in this study, is only on owner and agent behavior.

Hypothesis 2: TCs are higher if the transaction environment is uncertain.

Uncertainty of Owner's Behavior (UOOB)

The UOOB shows the importance of the owner's relationship with other parties (designers, contractors, and suppliers, etc.). The owners' good relationship with other parties reduces the chances 
of litigation in the process of contracting (Li et al., 2013) which reduces the TC. The responsibility of the owner is to make a comprehensive work scope at the pre-contract phase. If the contract specifications are not prepared in detail it may cause various post-contract change orders which incurred TC to the owner through various claims from the contractor (Onyango, 1993). Owner good relationship is characterized by timely payments to the contractor, which likely reduce the frequency of contractors' claims and fewer chances of legal disputes from project sites (Ozorhon, Arditi, Dikmen, \& Birgonul, 2010) that reduces the TC. Similarly, the owners' previous experience to deal with similar nature of projects helps them to tackle contractors' frequency of request for information from the project site (Ozorhon et al., 2010). The ability of an organization to implant its plan with minimum cost is considered organizational efficiency. The efficient organization arranges the scale of operation at minimum cost (Mosheim, 2002), which reduces the TC. It can infer that the owner's inadequate relationship with other parties, frequent change orders, late payments to the contractor, owner lack of work experience, and organizational inefficiency may increase the TC. Based on these, it is expected that UOOB would positively affect the TC of construction projects.

Hypothesis 3: TCs are higher if the owner's behavior is uncertain.

\section{Uncertainty of Contractor Behavior (UOCB)}

The UOCB can be measured by the following indicators. For instance, a qualified contractor can show lawful bidding behavior. Sometimes unlawful contractor shows unbalance bidding behavior which is challenging for the owner to detect on pre-contract phase (Arditi \& Chotibhongs, 2009). If the unbalance bidder is awarded a project in competitive bidding, may cause overall project cost escalation. Similarly, the owner failed to investigate the bidding behavior, in which a contractor as a part of pre-contract settlement with other bidders wins the contract at higher rates which likely cost to the owner, hence increase in TC (Chotibhongs \& Arditi, 2012). The contractor relationship with the sub-contractor is important because challenging and problematic relationships between them may negatively affect general contractor performance, the weak relationship of both parties may enhance TC (Manu, Ankrah, Chinyio, \& Proverbs, 2015). During project execution differences between the contracting parties are inevitable. The reason for the difference between them may arise on the issue of frequency of claims from the project site. Moreover, the disagreement of owner and contractor while settling the issues on claim evaluation and to reach on equilibrium can increase TC ( $\mathrm{Li}$ et al., 2013). Contracting parties acknowledge the worth of a good relationship between them but the contractor's strong relationship with the owner is hard to achieve which decreases cooperation and increases disagreement; the destabilize working relations may incur TC (Bresnen \& Marshall, 2000).

If a contractor is qualified enough to do a job, display a lawful bidding behavior, good relationship with sub-contractor, harmonious relationship with the previous owner, and enough experience of a similar project can reduce the TC. It is expected that uncertain contractor behavior would have a positive effect on TC in construction projects.

Hypothesis 4: TCs is higher if the Contractor's behavior is uncertain.

\section{Research Methodology}

The purpose of this study is to evaluate the determinants of uncertainty factors that escalate TC in highway construction projects in developing countries like Pakistan. The first step of the research was a literature review and proposition of conceptual model. A survey questionnaire was designed for respondents to evaluate the influences on UOCP, UOTE, UOOB, and UOCB based on their experience. To check the research hypothesis on the research model this study has applied partial least square structural equation modeling (PLS-SEM) (Hair Jr, Hult, Ringle, \& Sarstedt, 2016).

In this study, eighteen variables were adopted from (Guo et al., 2016) and customized to develop a survey questionnaire (Table 1). For clarity and validation of the survey questionnaire, a pilot study with experienced academicians and practitioners was conducted. The survey questionnaire was refined as per their recommendations to make it more understandable for the respondents. The data collection generally comprises several methods such as postal services, mail, telephone, interviews, and self-administered i.e., hand-delivered. However, in this research, three survey methods were used, for instance, questionnaires were sent through email and postal services and also self-administered survey method to collect a large number of data. The survey questionnaire was designed in such a way that each question was given a 5-point Likert scale (1-5) for the respondents to choose their importance ( 1 for strongly disagree and 5 for strongly agree). 
For sampling, a list of respondents was acquired from provincial and federal public-sector organizations of Pakistan. It was also ensured that the respondents had sufficient experience on highway construction projects. The samples were randomly selected for the distribution of the questionnaire. The survey questionnaires were disbursed among the project managers, regional engineers, and associate engineers who worked in the highway construction projects. Table 2 shows the survey questionnaires received from five regions, namely, Balochistan, Sindh, Khyber Pakhtunkhwa (KPK), Punjab, and GB. Based on our previous experience, survey questionnaires by hand (198) were distributed more, by postal carriers (52) and by email (108). The total number of questionnaires returned over four months (July 2020- Oct 2020) was 242, representing 195 by hand, 12 by postal carriers, and 35 by email; a total of 12 questionnaires were discarded because of incomplete or invalid information and physical loss. A total of 230 out of 358 questionnaires were considered valid, and a $64 \%$ response rate is deemed reliable for further analysis (Aibinu \& Odeyinka, 2006).

Table 1. The Summary of Construct and Initial Measurement

\begin{tabular}{|c|c|c|}
\hline Uncertainty & Codes & Uncertainty Measuring Indicator \\
\hline \multirow{3}{*}{$\begin{array}{l}\text { Uncertainty of construction projects } \\
\text { (UOCP) }\end{array}$} & UOCP1 & Project completeness \\
\hline & UOCP 2 & Project complexities \\
\hline & UOCP 3 & Project uncertainties \\
\hline \multirow{5}{*}{$\begin{array}{l}\text { Uncertainty of } \\
\text { environment (UOTE) }\end{array}$} & UOTE1 & Contract risk allocation \\
\hline & UOTE 2 & Integration between design and construction \\
\hline & UOTE 3 & Contract incentive and disincentive clauses \\
\hline & UOTE 4 & Contractor early engagement \\
\hline & UOTE 5 & Competitive procurement process \\
\hline \multirow{5}{*}{$\begin{array}{l}\text { Uncertainty of owner behavior } \\
\text { (UOOB) }\end{array}$} & UOOB 1 & Owner relationship with parties \\
\hline & UOOB 2 & Owner change orders \\
\hline & UOOB 3 & Owner delay payments \\
\hline & UOOB 4 & Owner experience in similar projects \\
\hline & UOOB 5 & Organizational efficiency \\
\hline \multirow{5}{*}{$\begin{array}{l}\text { Uncertainty of Contractor behavior } \\
\text { (UOCB) }\end{array}$} & UOCB1 & Contractor bidding behavior \\
\hline & UOCB2 & Contractor relationship with sub-contractor \\
\hline & UOCB3 & Contractor experience in similar projects \\
\hline & UOCB4 & Contractor relationship with the previous client \\
\hline & UOCB5 & Contractor frequency of claims \\
\hline \multirow[t]{3}{*}{ Transaction Cost (TC) } & $\mathrm{TC} 1$ & Project design (PD) \\
\hline & $\mathrm{TC} 2$ & Project procurement $(\mathrm{PP})$ \\
\hline & TC3 & Project Execution (PE) \\
\hline
\end{tabular}

Table 2. Summary of Data Collection

\begin{tabular}{lllllll}
\hline & Provinces & & & & & Total \\
\cline { 2 - 7 } Designation & Balochistan & Sindh & KPK & Punjab & GB & \\
\hline Executive Engineer & 10 & 13 & 22 & 26 & 7 & 78 \\
Resident Engineer & 30 & 32 & 20 & 25 & 16 & 123 \\
Consultants & 05 & 06 & 5 & 10 & 03 & 29 \\
Total & 45 & 51 & 47 & 61 & 26 & 230 \\
\hline
\end{tabular}

Description of measurement tools

Model validation

\section{Evaluation of measurement model}

To examine the reflective measurement model and structural relationship between uncertainties and TC this study has used SmartPLS 3.0 software (Ringle et al., 2005). For the data reliability, Cronbach's alpha is calculated, which shows that all the items in the construct have a similar range and meaning. In Table 3, our calculation meets the acceptable threshold for Cronbach's alpha i.e 0.70 (Field, 2009). It is recommended to use both Cronbach's alpha and composite reliability for internal consistency. The cut-off value for composite reliability is 0.70 which is considered appropriate for different factor loading. The composite reliability for the constructs should be more than and equal to 0.70 which has confirmed individual indicator reliability in this study. The AVE value is used to check the convergent validity and discriminant validity. The threshold value is 0.5 (Ringle, 2011) and data results show that both are valid. For further evaluation of discriminant validity of SEM, this study has used the Fornell-Larcker criterion test (Fornell \& Larcker, 1981). This can be understood if we find that latent variables are independent of each other or not (Hair Jr et al., 2016). It requires to 
compare the square root of the AVE value of each latent variable with the correlation between the latent variable. Table 3 demonstrated the square root of AVE which shows that each construct is greater than the correlation between the constructs which confirm discriminant validity.

Table 3: Validation score and latent variable correlation

\begin{tabular}{lllllllll}
\hline & TC & UOCP & UOTE & UOCB & UOOB & AVE & $\begin{array}{l}\text { Composite } \\
\text { Reliability }\end{array}$ & $\begin{array}{l}\text { Cronbach's } \\
\text { Alpha }\end{array}$ \\
\hline TC & 0.836 & & & & & 0.698 & 0.874 & 0.783 \\
UOCP & 0.644 & 0.869 & & & & 0.756 & 0.903 & 0.837 \\
UOTE & 0.645 & 0.326 & 0.836 & & & 0.699 & 0.921 & 0.892 \\
UOCB & 0.634 & 0.290 & 0.246 & 0.869 & & 0.754 & 0.939 & 0.919 \\
UOOB & 0.679 & 0.315 & 0.298 & 0.338 & 0.862 & 0.743 & 0.935 & 0.914 \\
\hline
\end{tabular}

Evaluation of structural model

For the analysis of the structural model. The first step is to calculate and analysis of the coefficient of determination $\left(\mathrm{R}^{2}\right)$. It evaluates the relationship of latent variable explained variance to its total variance (Urbach \& Ahlemann, 2010). A higher value of $\mathrm{R}^{2}$ is desirable and depends upon the research context (Hair, Black, Babin, Anderson, \& Tatham, 1998) but for standardization, the value would be considered substantial at $67 \%$, average at 33\%, and weak at $19 \%$ (Urbach \& Ahlemann, 2010). The $R^{2}$ result of our study shows 0.888 and $R^{2}$ adjusted is 0.886 both are considered substantial. The next step is the calculation of $\beta$ which describes the magnitude, significance, and strength of the relationship between two latent variables (Urbach \& Ahlemann, 2010). Using Tstatistics, we intended to know if the $\beta$ of the inner model is significant or not at a significance level of $(5 \%)$. The $\beta$ will be significant if the $\mathrm{T}$ statistics is larger than 1.96 . Table 4 shows the calculation where all $\beta$ in the inner model is significant.

Table 4: Calculation of Path Coefficient ( $\beta$ )

\begin{tabular}{|c|c|c|c|c|c|c|}
\hline & & $\begin{array}{l}\text { Original } \\
\text { Sample }(\mathrm{O})\end{array}$ & $\begin{array}{l}\text { Standard } \\
\text { Deviation } \\
\text { (STDEV) }\end{array}$ & $\begin{array}{l}\text { T Statistics } \\
(|\mathrm{O} / \mathrm{STDEV}|)\end{array}$ & P Values & $\begin{array}{l}\text { Statistical } \\
\text { Inference }\end{array}$ \\
\hline UOCP ->TC & 0.319 & & 0.027 & 11.695 & 0.000 & Significan \\
\hline UOTE ->TC & 0.351 & & 0.028 & 12.687 & 0.000 & Significan \\
\hline UOCB->TC & 0.333 & & 0.029 & 11.407 & 0.000 & Significan \\
\hline UOOB->TC & 0.361 & & 0.026 & 13.756 & 0.000 & Significan \\
\hline
\end{tabular}

The next step is to calculate the effect size $\left(\mathrm{f}^{2}\right)$ shown in Table 5 to measure if the independent latent variable has a substantial effect on the dependent variable. The provided ranges are $2 \%, 15 \%$ and $35 \%$ indicates the weak, moderate, and strong effect of predictors variables respectively on the structural model. Table 4 shows that the $\mathrm{f}^{2}$ values have a strong effect. The last step is a calculation for predictive relevance $\left(\mathrm{Q}^{2}\right)$ using the blindfolding procedure on smart pls. The proposed threshold value for the predictive relevance $\mathrm{Q}^{2}$ should be greater than zero (Urbach \& Ahlemann, 2010). The value of $\mathrm{Q}^{2}$ in this study is 0.5 which shows that the model has a positive predictive relevance.

Table 5: Effect size $\left(\mathrm{f}^{2}\right)$

\begin{tabular}{ll}
\hline & $\mathrm{f}^{2}$ \\
\cline { 2 - 2 } Uncertainty of Construction Project (UOCP) & 0.745 \\
Uncertainty of Transaction Environment (UOTE) & 0.928 \\
Uncertainty of Contractor's Behavior (UOCB) & 0.834 \\
Uncertainty of Owner's Behavior (UOOB) & 0.939 \\
\hline
\end{tabular}

The hypotheses that UOCP, UOTE, UOOB, and UOCB influence the TC was tested on PLS-

SEM. Figure 5 shows the measurement model and structural model indicators show that the hypothesis is statistically significant and is acceptable. The $\mathrm{R}^{2}$ value of the final SEM model was 0.888 which shows that $88 \%$ of the uncertainty factors affect the TC. The results of the hypotheses from $\mathrm{H} 1$ to $\mathrm{H} 4$ were all significant and therefore accepted. The result of this study assists to understand the uncertainty in highway construction projects and its influence on TC. 


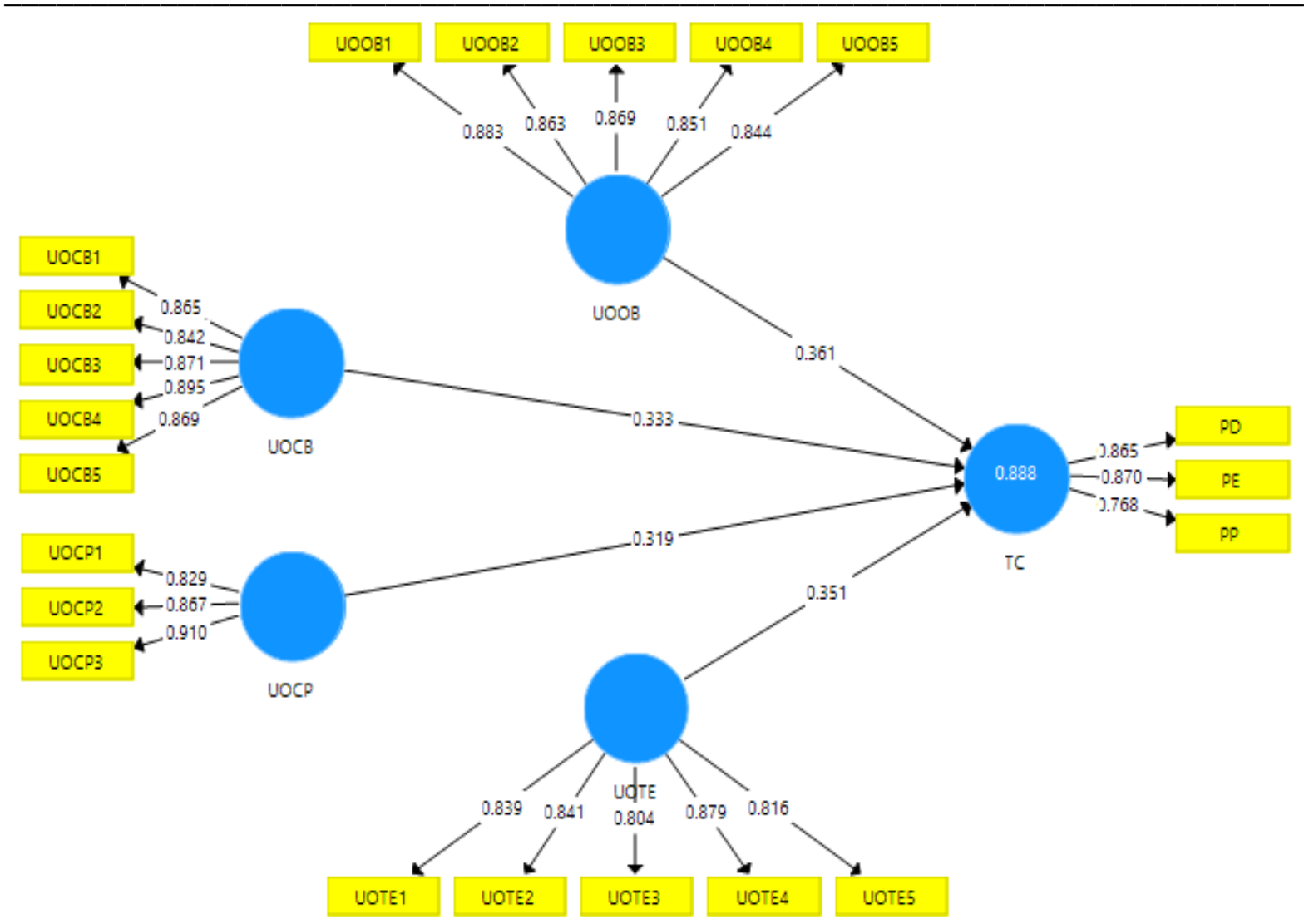

Figure 5: Final Standardized SEM Model

\section{Discussion}

The purpose of this research is to find the determinants of uncertainty factors that influence the TC borne by the owner in highway construction projects. The data analysis shows that TC is significantly higher for all the hypothesis and verified that uncertainty increase TC (Table 4). It can be further validated from $\beta$ of an inner model where all the hypotheses shown significant (T-statistics is larger than 1.96). The SEM suggested that UOOB is considered more critical $(\beta=0.361, T=13.756, p=$ $0.000)$ for TC escalation. The influence of UOTE was found second highest $(\beta=0.351, \mathrm{~T}=12.687, \mathrm{p}$ $=0.000)$ for TC escalation. The path coefficient of UOCB $(\beta=0.333, \mathrm{~T}=11.407, \mathrm{p}=0.000)$ and UOCP $(\beta=0.319, T=11.695, p=0.000)$ both show least effect on TC. However, in this study, UOOB was found to have the greatest factor influencing TC, subsequently, UOCB was found to have the least influence on the TC in Pakistan. This finding contradicts the study conducted in a developed country which found that UOTE is the most critical factor influence the TC (Guo et al., 2016).

The detailed analysis of UOOB shows that it is one of the most critical determinants of uncertainty that can enhance the TC. The first most influential factor is the "owner's relationship with other parties" (0.883). The construction industry of Pakistan publicly announced the projects and use traditional project delivery methods. The owner at a time deal with multiple contractors, designers, government agencies, and suppliers. The good relationship of the owner with such parties likely reduces the probability of litigation cases against the owner hence reduces extra expenditure in the form of legal fees (Arditi \& Pulket, 2010). The uncertainties increase due to the uncooperative relationship of contracting parties and the severity of conflicts between them and it can be used as a yardstick to measure TC. The second most important factor under UOOB is "owner delay payments (0.869)" which shows the owner's fund management incompetence in a timely arrangement of payments to the contractor. The contractor due to delayed payments borrows money which enhances the financial cost to the contractor ( $\mathrm{Li}$ et al., 2015). The delay payments to the main contractor have a trickle-down effect when it comes to making payments to subcontracting projects eventually put an additional burden on the main contractor (Arditi \& Chotibhongs, 2005). This study also identifies third-factor "owner change orders $(0.863)$ ", which shows incomplete and unclear work scope that causes post-contract change orders and potentially a conflicting situation between the contracting parties. The change orders frequency and its financial impact in terms of cost escalation are also 
discussed in the literature (Günhan, Arditi, \& Doyle, 2007). The fourth factor is the experience of contracting parties in similar projects $(0.851)$, which shows the deficiency of required experience of the working staff in the organizations. If an organization incorporates the learning for future projects, it can reduce the frequency of contractor's requests for information ( $\mathrm{Li}$ et al., 2015). But organizations are not dynamic to keep the learning and experience record for future projects to cope with uncertainty (Perminova et al., 2008) which increases the TC. The last factor is the lack of organizational efficiency $(0.844)$. This can be achieved if the organization minimizes inputs to get a set of required output. If the owner has a strained relationship with other parties, delay payments, frequent change orders, little or inexperienced staff depicts owner uncertainty, hence cause TC escalation.

The UOOB indirectly influences the UOTE. According to the path coefficient, UOTE was found to have a moderate influence on the TC. Previous studies supported the effect of transaction environment (E. Diekmann \& Girard, 1995; Walker \& Pryke, 2009) on cost escalation. The most influential sub-criteria of UOTE is found to be "contractor early engagement" (0.879). The uncertainty can be reduced if the contractor is engaged early in the design phase completing the project specification may contribute to improves the collaboration of both parties in the process of design and construction which shows similar observation made from previous studies in different countries (Eriksson \& Pesämaa, 2007; Manu et al., 2015; Rajeh et al., 2015). Also, the incentives and disincentive clauses in the contract agreement and proper risk allocation to the contractor will help to reduce the UOTE.

The influence of UOCB on the TC is indirectly influenced by the owner's behavior. From the path coefficient, the influence of UOCB on TC is low. The contractor behavior is manifested from the UOOB and UOTE. The uncertainty of the owner and transaction environment increases the probability to transfer more uncertainty to the contractor. The intolerant contractor encounters more uncertainty with opportunism (Atkinson et al., 2006). For instance, if the contractor cannot meet the possible contingencies may ask for additional payments, fall behind the schedule and proceed for bankruptcy (Chang \& Ive, 2007). It is advised to build trust between the contracting parties to manage the uncertainty (Atkinson et al., 2006). The trust can be developed to reduce the UOCB when the contractor has a good relationship with the previous subcontractor and client.

According to the path coefficient measure, UOCP was found to have the least influence on TC. In construction projects, a small problem could become critical and complicated if early identifications are not made. It requires effective decision-making, problem-solving, and negotiation skills of the project participants (Mitropoulos \& Howell, 2001). The project complexities increase the uncertainties which can influence the TC (Farajian, 2010; Jobin, 2008). Project complexity can be resolved when the owner focuses more on the design phase to make a complete design incorporating qualitative and quantitative aspects. The detailed specifications of design before contracting out of a project reduce the construction project uncertainty itself ( $\mathrm{Li}$ et al., 2015). The latent variable that measures TC in a construction project on project cycle i.e PD, PP, and PE have loading value 0.865 , 0.768 , and 0.865 respectively. The data shows that uncertainties influence the TC in all phases of the project life cycle, but the PE phase of the project life cycle is more prone to escalate the TC.

\section{Conclusion}

All projects face uncertainty to a certain degree during their operations. Uncertainties are not bad for projects because it is characterized as evolution for better performance (Perminova et al., 2008). The highway construction projects are known to have a complex and risky environment and are more likely prone to uncertainties especially in developing countries. In such situations, various precontract decisions may create post-contract disputes between the contracting parties such as change orders, incomplete information, and work acceleration, etc. cause TC escalation. This study has adopted various definitions of TC from the literature borne by an owner and conducted an empirical study in Pakistan to identify the determinants of uncertainty that influence TC. The data was collected using a survey questionnaire from public-sector organizations of Pakistan and analyzed using PLSSEM. This study verifies the reliability and validity of the study and presents the findings below.

In Pakistani highway construction, various uncertainties are the driving force to escalate TC, and found that UOOB is the core construct of the model, which is linked to the UOTE, UOCB, and UOCP. Figure 2 shows factor loading and path coefficient according to which UOOB highly affects TC. It can be reduced if the owner has a good relationship with other parties, timely payment to the 
contractor, reduce change orders, enough experience of staff in similar projects, which can not only increase the organization efficiency but also reduce the TC in highway projects. UOTE was found to moderately affect the TC through the owner's behavior. According to the figure 2 path coefficient, if the owner engages the contractor early in design, integration between design and construction, proper risk allocation, competitive procurement, and incentive and disincentive options can reduce the TC. This study confirms that TC is escalated more in the post-contract phase of the project cycle. The complete arrangement made in the pre-contract phase can help reducing uncertainty in the postcontract phase resultantly fewer chances of TC escalation.

\section{Implications and Limitations}

This study provides evidence of uncertainties and their influence on TC borne by the owner in highway construction projects. This study suggests controlling owner's uncertain behavior through developing a good relationship with contracting parties, focuses to complete project scope to reduce post-contract change-orders, assure the availability of funds to make timely payments, enhances similar project experience to improve overall organizational efficiency. The efficiency can increase hiring third-party services to make the good scope, employee training and developing a good relationship with the partners. This study also provides implications to reduce the uncertainty influence on TC to bring the cost-efficiency in construction projects. Proper attention is also needed to the transaction environment and assessment of the contractor's behavior. This research used only the organizational perspective of public construction projects. In the future, richer identification and analyses can be made by incorporating the contractors' and other stakeholders' views. Without incorporating the environmental differences of public and private sector construction projects, capturing only public sector construction projects is insufficient for drawing general conclusions.

\section{References}

Aibinu, A. A., \& Odeyinka, H. A. (2006). Construction Delays and Their Causative Factors in Nigeria. Journal of Construction Engineering and Management, 132(7), 667-677.

Ali, Z., Zhu, F., \& Hussain, S. (2018). Identification and Assessment of Uncertainty Factors that Influence the Transaction Cost in Public Sector Construction Projects in Pakistan. Buildings, $8(11), 157$.

Arditi, D., \& Chotibhongs, R. (2005). Issues in Subcontracting Practice. Journal of Construction Engineering and Management, 131(8), 866-876.

Arditi, D., \& Chotibhongs, R. (2009). Detection and prevention of unbalanced bids. Construction Management and Economics, 27(8), 721-732.

Arditi, D., \& Pulket, T. (2010). Predicting the Outcome of Construction litigation Using an Integrated Artificial Intelligence Model. Journal of Computing in Civil Engineering, 24(1), 73-80.

Atkinson, R., Crawford, L., \& Ward, S. (2006). Fundamental uncertainties in projects and the scope of project management. International Journal of Project Management, 24(8), 687-698.

Bresnen, M., \& Marshall, N. (2000). Building partnerships: Case studies of client-contractor collaboration in the UK construction industry. Construction Management and Economics, 18(7), 819-832.

Broome, J., \& Perry, J. (2002). How practitioners set share fractions in target cost contracts. International Journal of Project Management, 20(1), 59-66.

Chang, C. Y., \& Ive, G. (2007). Reversal of bargaining power in construction projects: Meaning, existence, and implications. Construction Management and Economics, 25(8), 845-855.

Cheung, S. O., \& Pang, K. H. Y. (2013). Anatomy of Construction Disputes. Journal of Construction Engineering \& Management, 139(1), 15-23.

Chotibhongs, R., \& Arditi, D. (2012). Analysis of collusive bidding behavior. Construction Management and Economics, 30(3), 221-231.

Coggan, A., Buitelaar, E., Whitten, S., \& Bennett, J. (2013). Factors that influence transaction costs in development offsets: Who bears what and why? Ecological Economics, 88, 222-231.

Collier, P., \& Gunning, J. W. (1999). Explaining African economic performance. Journal of Economic Literature, 37(1), 64-111.

Diekmann, E., \& Girard, M. J. (1995). Are Contract Disputes Predictable? Journal of Construction Engineering and Management, 121, 355-363.

Diekmann, J. E., \& Nelson, M. C. (1985). Construction claims: frequency and severity. Journal of Construction Engineering and Management, 111(1), 74-81. 
El-Sayegh, Sameh M., \& Mansour, M. H. (2015). Risk Assessment and Allocation in Highway Construction Projects in the UAE. Journal of Management in Engineering, 31(6), 04015004.

El-Sayegh, Sameh Monir. (2008). Risk assessment and allocation in the UAE construction industry. International Journal of Project Management, 26(4), 431-438.

Eriksson, P. E., \& Pesämaa, O. (2007). Modelling procurement effects on cooperation. Construction Management and Economics, 25(8), 893-901.

Farajian, M. (2010). Transaction cost model for US infrastructure public-private partnerships. (M.Sc Thesis), University of Maryland, Maryland, USA.

Field, A. (2009). Discovering Statistics Using SPSS. California, USA: Sage, publications.

Fornell, C., \& Larcker, D. F. (1981). Evaluating structural equation models with unobservable variables and measurement error. Journal of Marketing Research, 18(1), 39-50.

Galbraith, J. R. (1973). Designing complex organizations. Addison-Wesley Longman Publishing Co., Inc.

Greenwood, D., \& Yates, D. J. (2006). The determinants of successful partnering: A transaction cost perspective. Journal of Construction Procurement, 12(1), 4-12.

Grimm, C. M., Lee, H., \& Smith, K. G. (2006). Strategy as action: Competitive dynamics and competitive advantage. New York, USA: Oxford University Press.

Günhan, S., Arditi, D., \& Doyle, J. (2007). Avoiding Change Orders in Public School Construction. Journal of Professional Issues in Engineering Education and Practice, 133(1), 67-73.

Guo, L., Li, H., Li, P., \& Zhang, C. (2016). Transaction costs in construction projects under uncertainty. Kybernetes, 45(6), 866-883.

Hair, J. F., Black, W. C., Babin, B. J., Anderson, R. E., \& Tatham, R. L. (1998). Multivariate data analysis (Vol. 5). New Jersey, USA: Prentice-Hall.

Hair Jr, J. F., Hult, G. T. M., Ringle, C., \& Sarstedt, M. (2016). A primer on partial least squares structural equation modeling (PLS-SEM). Sage Publications.

Hillebrandt, P. M., \& Hughes, W. (2000). What are the Costs of Procurement and Who bears Them? In Proceedings 2nd International Conference on Construction in Developing Countries. Gaborone: Botswana National Construction Industry Council and University of Botswana.

Hofstede, G. (2003). Culture's consequences: Comparing values, behaviors, institutions, and organizations across nations. Thousand Oaks, CA Sage publications.

Jin, X.-H., \& Zhang, G. (2011). Modelling optimal risk allocation in PPP projects using artificial neural networks. International Journal of Project Management, 29(5), 591-603.

Jobin, D. (2008). A Transaction cost-based approach to partnerships performance evaluation. Evaluation, 14(4), 437-465.

Li, H., Arditi, D., \& Wang, Z. (2015). Determinants of transaction costs in construction projects. Journal of Civil Engineering and Management, 21(5), 548-558.

Li, H., Arditi, D., \& Zang, Z. (2013). Factors that affect transaction costs in construction projects. Journal of Construction Engineering and Management, 139(1), 60-68.

Manu, E., Ankrah, N., Chinyio, E., \& Proverbs, D. (2015). Trust influencing factors in main contractor and subcontractor relationships during projects. International Journal of Project Management, 33(7), 1495-1508.

Marcus, A., \& Cohen, A. (2017). Management Strategy: Achieving sustained competitive advantage. New York, USA: McGraw-Hill/Irwin;

Milward, H. B. (1996). Symposium on the Hollow State: Capacity, Control, and Performance in Intercrganizational Settings. Journal of Public Administration Research and Theory, 6(2), 193-195.

Miranda, R., \& Lerner, A. (1995). Bureaucracy, organizational redundancy, and the privatization of public services. Public Administration Review, 55(2), 193-200.

Mitropoulos, P., \& Howell, G. (2001). Model for understanding, preventing and resolving project disputes. Journal of Construction Engineering and Management, 127(3), 223-231.

Mosheim, R. (2002). Organizational type and efficiency in the Costa Rican coffee processing sector. Journal of Comparative Economics, 30(2), 296-316.

Mysen, T., Svensson, G., \& Payan, J. M. (2011). The key role of opportunism in business relationships. Marketing Intelligence \& Planning, 29(4), 436-449.

Onyango, D. (1993). Reduction in Conflicts in Construction. MSc Report. (MSc report) 
Loughborough University of Technology, Loughborough, UK.

Ozorhon, B., Arditi, D., Dikmen, I., \& Birgonul, M. (2010). Performance of International Joint Ventures in Construction. Journal of Management in Engineering, 26(4), 209-222.

Perminova, O., Gustafsson, M., \& Wikstrom, K. (2008). Defining uncertainty in projects - a new perspective. International Journal of Project Management, 26(1), 73-79.

Perry, J. L., \& Babitsky, T. (1986). Comparative Performance in Urban Bus Transit: Strategies Assessing Privatization. Public Administration Review, 46(1), 57-66.

Pride, W., Elliott, G., Rundle-Thiele, S., Waller, D., Paladino, A., \& Ferrell, O. C. (2006). Marketing: core concepts and applications. Brisbane, Australia: John Wiley.

Rajeh, M., Tookey, J. E., \& Rotimi, J. O. B. (2015). Estimating transaction costs in the New Zealand construction procurement. Engineering, Construction and Architectural Management, 22(2), $242-267$.

Reilly, J., \& Brown, J. (2004). Management and control of cost and risk for tunneling and infrastructure projects. Tunneling and Underground Space Technology, 19(4-5), 330.

Reve, T., \& Levitt, R. E. (1984). Organization and governance in construction. International Journal of Project Management, 2(1), 17-25.

Ringle, C. M. (2011). PLS-sem : Indeed a silver bullet PLS-SEM : Indeed a Silver Bullet. The Journal of Marketing Theory and Practice, 19(2).

Shen, L. Y., Wu, G. W. C., \& Ng, C. S. K. (2001). Risk Assessment for Construction Joint Ventures in China. Journal of Construction Engineering and Management, 127(1), 76-81.

Shin, H.-D. (2003). The Role of uncertainty in Transaction Cost and Resource-based theories of the firm. Dissertation (Ph.D.). Ohio State University, USA.

Turner, J. R., \& Keegan, A. (2001). Mechanisms of governance in the project-based organization: Roles of the broker and steward. European Management Journal, 19(3), 254-267.

Urbach, N., \& Ahlemann, F. (2010). Structural Equation Modeling in Information Systems Research Using Partial Least Squares Structural Equation Modeling in Information Systems Research Using Partial Least Squares. Journal of Information Technology Theory and Application, 11(2), 5-40.

Walker, F., \& Pryke, S. (2009). Role, Definition, and Dimensions of Incomplete Construction Contract Documents. Proceedings, RICS COBRA Research Conference, University of Cape Town, 1258-1275.

Weick, K. E. (1977). Enactment processes in organizations. New Directions in Organizational Behavior, 267, 300 .

Williamson, O. E. (1975). Markets and Hierarchies. New York, USA: Free press.

Williamson, O. E. (1985). The economic institutions of capitalism. Firms, market, relational contracting. New York: The Free Press.

Winch, G. (1989). The construction firm and the construction project: A transaction cost approach. Construction Management and Economics, 7(4), 331-345.

Wise, C. R. (1990). Public Service Configurations and Public Organization: Organization Design in the Post-Privatization Era. Public Administration Review, 50(2), 141-155.

Youker, R. (1992). Managing the international project. Journal of Project Management (1992), 10(4), 219-226. 